\title{
Surgical technique and results of cable graft interpositioning of the facial nerve in lateral skull base surgeries: experience with 213 consecutive cases
}

\author{
*Sampath Chandra Prasad, MS, DNB, FEB-ORLHNS, ${ }^{1}$ Karthikeyan Balasubramanian, MS," \\ Enrico Piccirillo, MD, ${ }^{1}$ Abdelkader Taibah, MD, ${ }^{1}$ Alessandra Russo, MD,1 Jingchun He, MD, PhD, ${ }^{1,2}$ \\ and Mario Sanna, MD' \\ 1Department of Otology \& Skull Base Surgery, Gruppo Otologico, Piacenza and Rome, Italy; and 2Department of \\ Otorhinolaryngology, Shanghai First People's Hospital, Shanghai Jiao Tong University, Shanghai, People's Republic of China
}

\begin{abstract}
OBJECTIVE The aim in this study was to review the technique and outcomes of cable graft interpositioning of the facial nerve (FN) in lateral skull base surgeries.

METHODS The authors retrospectively evaluated data from patients who had undergone cable graft interpositioning after nerve sacrifice during skull base tumor removal between June 1987 and May 2015. All patients had undergone lateral skull base approaches to remove tumors at a quaternary referral center in Italy. Facial nerve function was evaluated before and after surgery using the House-Brackmann (HB) grading system.

RESULTS Two hundred thirteen patients were eligible for study. The mean follow-up was 44.3 months. The most common pathology was vestibular schwannoma (83 cases [39\%]), followed by FN tumor (67 cases [31\%]). Facial nerve tumors had the highest incidence of nerve interruption (67 [66\%] of 102 cases). Preoperative FN function was normal (HB Grade I) in 105 patients (49.3\%) and mild (HB Grade II) in 19 (8.9\%). At the last postoperative follow-up, 108 (50.7\%) of the 213 patients had recovered to Grade III nerve function. Preoperative HB grading of the FN was found to have a significant effect on outcome ( $p=0.002)$.

CONCLUSIONS Cable graft interpositioning is a convenient and well-accepted procedure for immediate restoration of the FN. The study results, over a large number of patients, showed that the stitch-less fibrin glue-aided coaptation technique yields good results. The best possible postoperative result achieved was an HB Grade III. The chances of a good postoperative result increase when FN function is normal preoperatively. Slow-growing tumors of the cerebellopontine angle had a favorable outcome after grafting. https://thejns.org/doi/abs/10.3171/2016.9.JNS16997
\end{abstract}

KEY WORDS facial nerve; cable nerve graft interpositioning; sural nerve; cerebellopontine angle; facial nerve tumor; House-Brackmann grading; peripheral nerve; skull base

$\mathrm{T}$ HE facial nerve $(\mathrm{FN})$ is one of the most important structures in the skull base, and its tortuous transtemporal course poses a formidable challenge to the lateral skull base surgeon. Saving or salvaging the FN is as important as tumor clearance itself because of the social, emotional, and psychological consequences of a damaged nerve, especially in young patients. Most skull base lesions either lie close to the FN, impinging and stretching it, or arise from the nerve itself. The development and evo- lution of FN rerouting techniques via infratemporal fossa approaches ${ }^{11-13,46}$ and transcochlear approaches ${ }^{21-23,45}$ have enabled exposure of the operating field without the need to interrupt the nerve when dealing with more deeply seated tumors in the skull base. Yet many intraoperative situations can lead to interruption of the FN intentionally or otherwise. For instance, facial nerve tumors (FNTs) intimately involve the nerve, making it almost impossible to save the FN. Once a nerve is interrupted, reconstruction

ABBREVIATIONS CPA = cerebellopontine angle; FN = facial nerve; FNT = FN tumor; HB = House-Brackmann; IAC = internal auditory canal; PBC = petrous bone cholesteatoma; SN = sural nerve; TJP = tympanojugular paraganglioma; VS = vestibular schwannoma.

ACCOMPANYING EDITORIAL See pp 627-630. DOI: 10.3171/2016.10.JNS162354.

SUBMITTED April 19, 2016. ACCEPTED September 7, 2016.

INCLUDE WHEN CITING Published online April 7, 2017; DOI: 10.3171/2016.9.JNS16997.

* Drs. Prasad and Balasubramanian contributed equally to this work. 
must be performed immediately to get the best results, either by means of a primary end-to-end coaptation or by a cable nerve graft interposition. ${ }^{36}$ In this article, we discuss our experience with intraoperative cable nerve graft interpositioning of the FN in one of the largest published series in the literature.

\section{Methods}

We performed a retrospective chart review of all patients who had undergone surgical management of the FN between June 1987 and May 2015 at the Gruppo Otologico, a quaternary referral center for skull base pathology in Piacenza and Rome, Italy. The inclusion criterion for this study was limited to repair of an interrupted FN using the sural nerve (SN) as an interposition cable graft in lateral skull base surgery. Exclusion criteria were as follows: 1) patients who underwent primary end-to-end coaptation, 2) patients who underwent other secondary reanimation procedures like facial-hypoglossal or facial-masseteric nerve coaptation, and 3) patients with incomplete records, less than 1 year of follow-up, or lost to follow-up. Given the referral nature of our practice, we had many patients from Europe, North Africa, and the Middle East, many of whom were not followed up at our center or were lost to follow-up and hence were excluded from this study. The study was cleared by the ethics committee of Casa Di Cura Hospital, Piacenza, Italy.

At the Gruppo Otologico, preoperative and postoperative FN function is classified according to the HouseBrackmann (HB) grading system. ${ }^{20}$ To precisely evaluate FN function, we take color photographs of a patient's face in 4 positions-facial muscles at rest, tight closure of the eyes, raised eyebrows, and smiling and pouting lips-both at the preoperative workup and during every postoperative visit. ${ }^{44}$ All skull base tumor cases are evaluated with highresolution CT as well as MRI with contrast enhancement. Angiography or MR angiography is performed in cases in which the tumor is in close association with important vasculature.

The surgical approaches used to treat tumors of the skull base include the translabyrinthine approach, retrosigmoid approach, transcochlear approach, transotic approach, middle cranial fossa approach, transmastoid approach, combined approaches, subtotal petrosectomy, infratemporal fossa approach, and transparotid approach. The detailed steps of the procedures have been described elsewhere. ${ }^{42}$

\section{Technique of Cable Graft Interposition}

An SN graft is harvested using a 3-cm curvilinear incision $1 \mathrm{~cm}$ behind the lateral malleolus. The incision is extended superiorly for a thicker portion of the nerve and inferiorly to obtain a bifurcated nerve (the SN branches into 2 or more branches anteroinferior to the malleolus) that may be needed for coaptation at the parotid bifurcation of the FN. The SN is carefully dissected with minimal trauma and always handled minimally with non-toothed forceps. The length of the FN defect is measured by placing a suture thread between the proximal and distal ends of the sectioned nerve, taking care to avoid any tension and to consider the pulsating brainstem. Parts of the SN that match the diameter of the cut ends of the FN are carefully selected. The SN is cleaned of its nerve sheath, and its edges are beveled at both ends by cutting it sharply with a knife. The proximal and distal cut ends of the FN are also cut sharply and beveled using sharp scissors. The proximal end is anastomosed first. The anastomoses at both the proximal and distal ends are achieved by placing the beveled ends of the FN and the graft together in apposition over a small piece of harvested temporalis fascia that is used to wrap and secure the anastomoses. Fibrin glue is applied after the coaptation and once again after wrapping the fascia over the coaptation. At the proximal coaptation in the cerebellopontine angle (CPA), care is taken to position the length of the graft along the brainstem surface against the fifth cranial nerve root for support (Fig. 1). The distal end is anastomosed in any remaining bone of the internal auditory canal (IAC) or by making a channel in the temporal bone. Fibrin glue is also applied at various points, wherever possible along the length of the graft, to further secure the graft. We use 9-0 monofilament sutures only for extratemporal epineurial coaptation (retroparotid and parotid). ${ }^{43}$

Definitive FN function was accepted as the main outcome measure. Five factors were taken into consideration in the analysis of nerve function: age, sex, preoperative HB grading, etiology of paralysis, and location of coaptation. All patients were followed-up for at least 1 year.

Data analysis was performed using the Statistical Package for the Social Sciences version 17 (SPSS Inc.). Univariate and multivariate analyses were used to test the significance of any difference between quantitative variables and chi-square tests for qualitative variables. A p value $<$ 0.05 was considered statistically significant.

\section{Results}

Of the 4192 lateral skull base procedures done for various pathologies in the specified study period, 330 patients

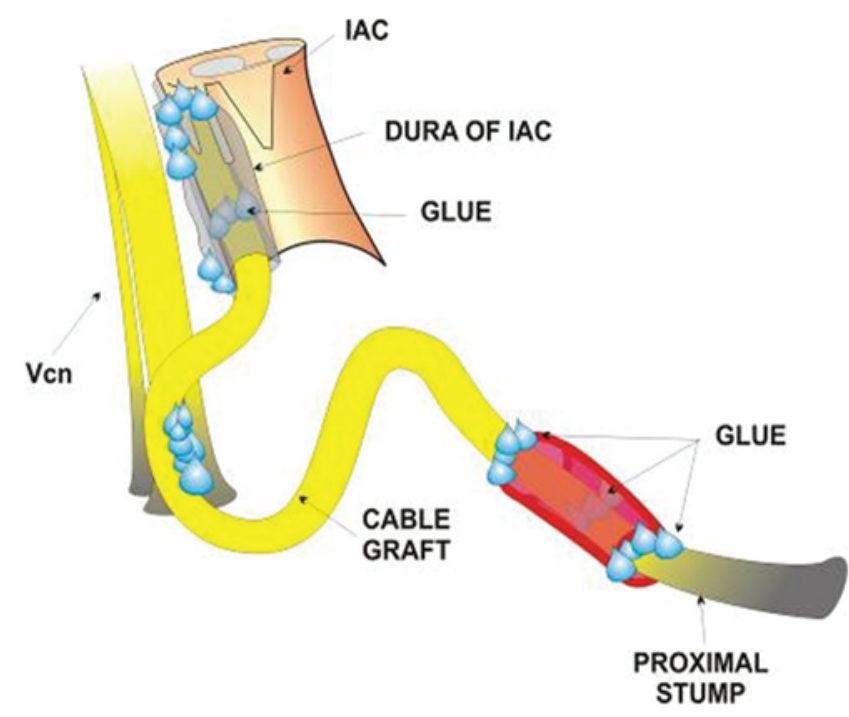

FIG. 1. At the proximal coaptation, care is taken to position the length of the graft along the brainstem surface against the fifth cranial nerve root. $V c n=$ fifth cranial nerve. Figure is available in color online only. 
TABLE 1. Pathologies in the skull base for which FN grafting was performed

\begin{tabular}{lcc}
\hline Pathology & $\begin{array}{c}\text { No. of Cases in Which Nerve } \\
\text { Graft Performed (\% of total no. } \\
\text { of cases of same pathology) }\end{array}$ & $\begin{array}{c}\text { Total No. of Cases } \\
\text { Treated at Gruppo } \\
\text { Otologico }\end{array}$ \\
\hline VS & $83(2.6)$ & 3208 \\
\hline FNT & $67(65.7)$ & 102 \\
\hline PBC & $29(14.4)$ & 201 \\
\hline TJP & $21(7.8)$ & 268 \\
\hline Meningioma & $10(4.2)$ & 240 \\
\hline TBM & $3(2.9)$ & 103 \\
\hline Other pathology & $0(0)$ & 70 \\
\hline Total & $213(5.1)$ & 4192 \\
\hline
\end{tabular}

TBM = temporal bone malignancy.

were subjected to surgical management of the FN that included cable nerve graft interpositioning, end-to-end coaptation, and nerve rehabilitation in a second stage like a facial-hypoglossal nerve coaptation or a facial-masseteric nerve coaptation. After applying the inclusion and exclusion criteria, 213 cases were eligible for inclusion and analysis in the study.

\section{Age, Sex, and Pathology}

The mean follow-up was 44.3 months (range 12-300 months). One hundred eight lesions were right sided and 105 were left sided. Patient ages ranged from 10 to 80 years with a mean of $45.7 \pm 13.9$ years. More than one-third (36.2\%) of the patients were 40 years of age or younger and were categorized as "young." One hundred six patients were males and 107 were females. The percentage of females $(60 \%)$ who recovered to HB Grade III function was significantly higher than the percentage of males who did $(46 \% ; p=0.04)$. The most common pathology was vestibular schwannoma (VS; 83 cases [39\%]), followed by FNT (67 cases [31\%]; Table 1). Facial nerve tumors had the highest incidence of nerve interruption (67 [66\%] of 102 cases), followed by petrous bone cholesteatomas (PBCs; 29 [14\%] of 201 cases). Vestibular schwannomas had the lowest incidence (83 [2.6\%] of 3208 cases). The length of the nerve grafts ranged from 1 to $6 \mathrm{~cm}$.

\section{Facial Nerve Results}

Preoperative FN dysfunction was absent (normal, HB Grade I) in 105 patients (49.3\%), mild (HB Grade II) in 19 (8.9\%), moderate (HB Grade III) in $23(10.8 \%)$, moderately severe (HB Grade IV) in 9 (4.2\%), severe (HB Grade V) in 7 (3.3\%), and complete (paralysis, HB Grade VI) in 50 (23.5\%). At the last postoperative follow-up, 108 (50.7\%) of the 213 patients had recovered to an HB Grade III nerve function, 46 (21.6\%) to Grade IV, 19 (8.9\%) to Grade V, and $40(18.8 \%)$ showed no recovery at all (Fig. 2).

Preoperative $\mathrm{HB}$ grading of the FN was found to have a significant effect on outcome ( $p=0.002$; Fig. 3 ). In a subgroup analysis, the outcome for preoperative HB Grade I function was good in all pathologies and was statistically significant in FNTs $(\mathrm{p}=0.02)$ and in tympanojugular paragangliomas (TJPs; $\mathrm{p}=0.01$ ). We analyzed the data to see if patient age had any effect on the recovery of FN function. Results showed that patients who recovered to HB Grade III were younger than those who fared worse (44.1 vs 49.5 years); however, this difference was not significant $(\mathrm{p}=0.16)$.

Of all the tumors encountered, the best results-that is, the maximum number of cases with an HB Grade IIIwere achieved in patients with meningiomas $(80 \%)$, followed by those with TJPs (57.1\%) and VSs (56.6\%; Fig. 4). The worst outcomes occurred in patients with PBCs and those with FNTs (37.9\% and 41.8\%, respectively, with HB Grade III outcome). Multivariate analysis showed significant differences between groups $(\mathrm{p}=0.001)$.

The site of coaptation was also analyzed based on the

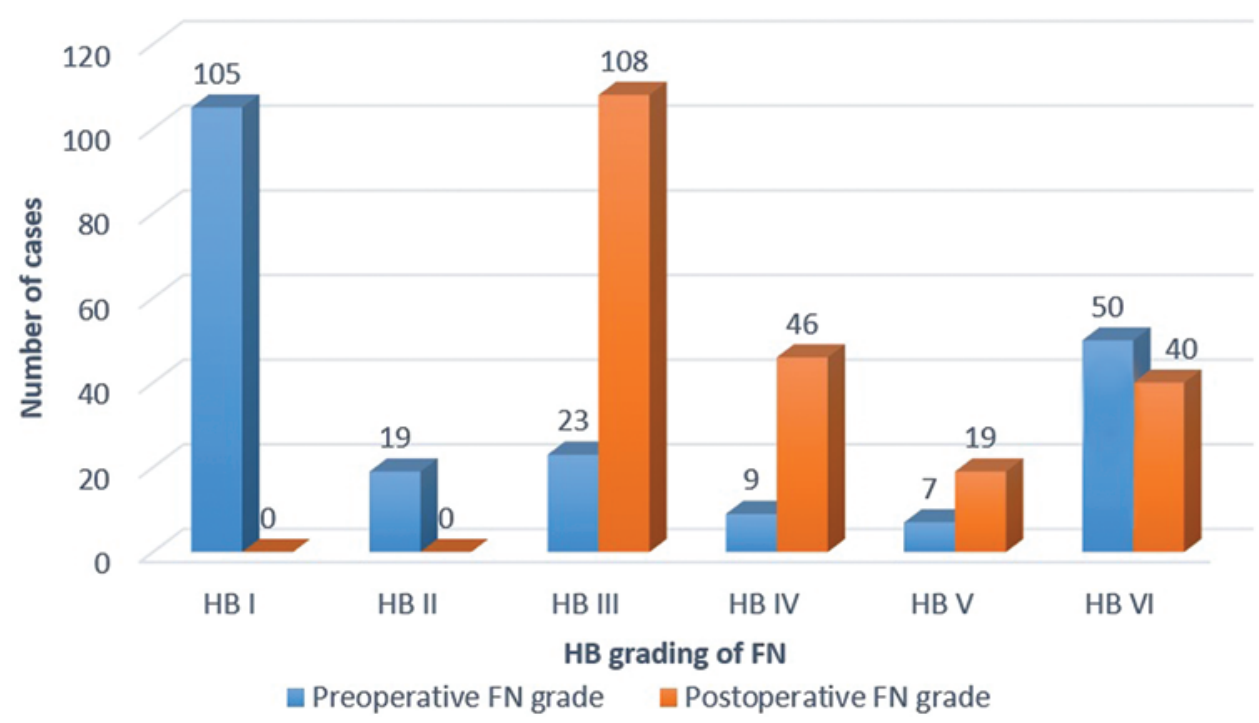

FIG. 2. Comparison between preoperative and postoperative FN results in all pathologies ( 213 cases). Figure is available in color online only. 


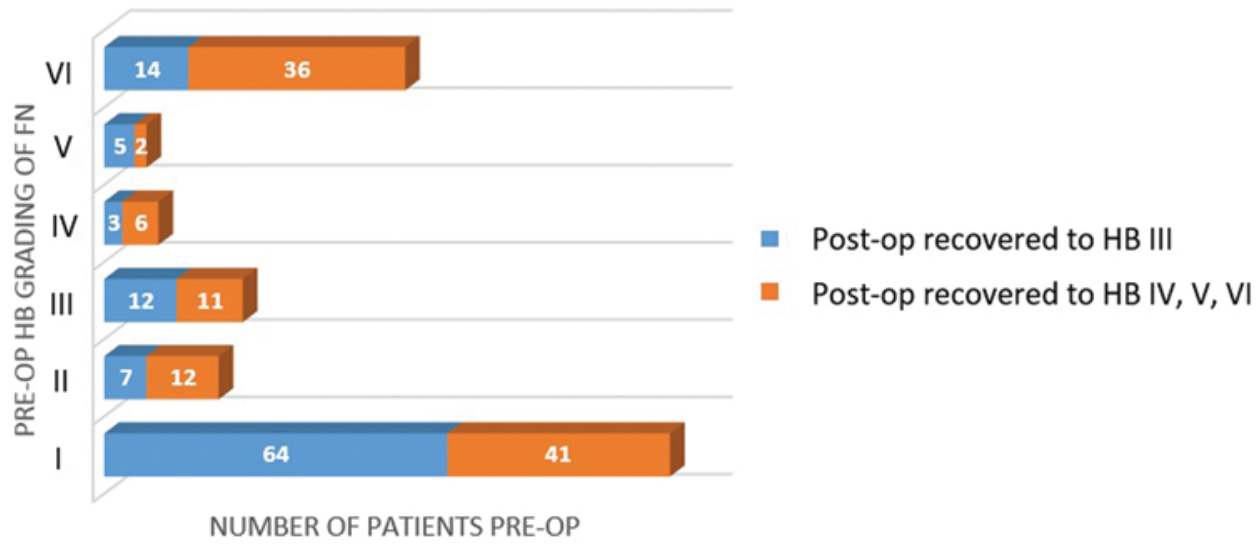

FIG. 3. House-Brackmann grading preoperatively and after SN graft interpositioning. Figure is available in color online only.

proximal and distal sites of coaptation. The 3 types of coaptation were designated as follows: 1) intradural coaptation, wherein the proximal coaptation was at the brainstem and the distal site was in the IAC (Fig. 5A); 2) transdural coaptation, wherein the proximal site was in the CPA or the IAC and the distal site was in the part of the temporal bone that remained after excision of the lesion (Fig. 5B), 3) extradural coaptation, wherein both the proximal and distal sites of coaptation were in the temporal bone or extratemporal (preparotid and parotid parts of the FN; Fig. 5C and D). In the multivariate analysis, there was a significant difference among the results in the 3 groups $(\mathrm{p}=0.001$; Fig. 6$)$. In a subgroup analysis, transdural coaptation was found to have a worse outcome as compared with both intradural and extradural coaptation. The difference between intradural and transdural coaptation as well as between transdural and extradural coaptation was also significant ( $\mathrm{p}=0.006$ and 0.01 , respectively). On subgroup analysis, $80 \%$ of the intradural coaptations had preoperative HB Grade I nerve function. In comparison, only $35 \%$ of the transdural and $3.22 \%$ of the extradural group had preoperative HB Grade I.

The length of the graft was measured using a suturing thread. The intradural graft measured from 3.5 to 4 $\mathrm{cm}$ long, transdural grafts were between 4.5 and $5.5 \mathrm{~cm}$ long, and extradural grafts were between 3 and $7 \mathrm{~cm}$ long.

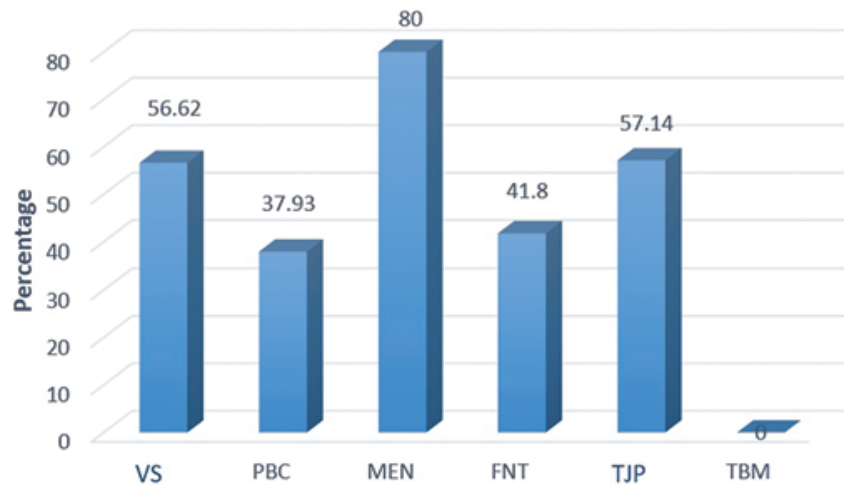

FIG. 4. Percentage of HB Grade III results achieved postoperatively in all pathologies encountered in the series. MEN = meningioma; TBM = temporal bone malignancy. Figure is available in color online only.
Note that $67.5 \%$ of the nerve grafts with a length $\leq 4 \mathrm{~cm}$, $17.59 \%$ of the nerve grafts with a length $4.1-5 \mathrm{~cm}$, and $14.81 \%$ of the nerve grafts with a length $\geq 5.1 \mathrm{~cm}$ recovered to HB Grade III. There was a significant difference among the 3 groups $(\mathrm{p}=0.01)$ in the multivariate analysis.

Finally, FN results were analyzed according to tumor size. In the VS subgroup, the tumors were between 3 and $5.5 \mathrm{~cm}$ in their maximum dimension. Larger tumors had worse postoperative FN function results; however, this finding was not statistically significant $(\mathrm{p}=0.81)$. In the PBC group, the massive type of lesion had a worse outcome than all other types, but again this finding was not statistically significant $(\mathrm{p}=0.13)$.

\section{Discussion}

Sural nerve cable graft interpositioning is a standard procedure for interruptions of the $\mathrm{FN}$ in the skull base.

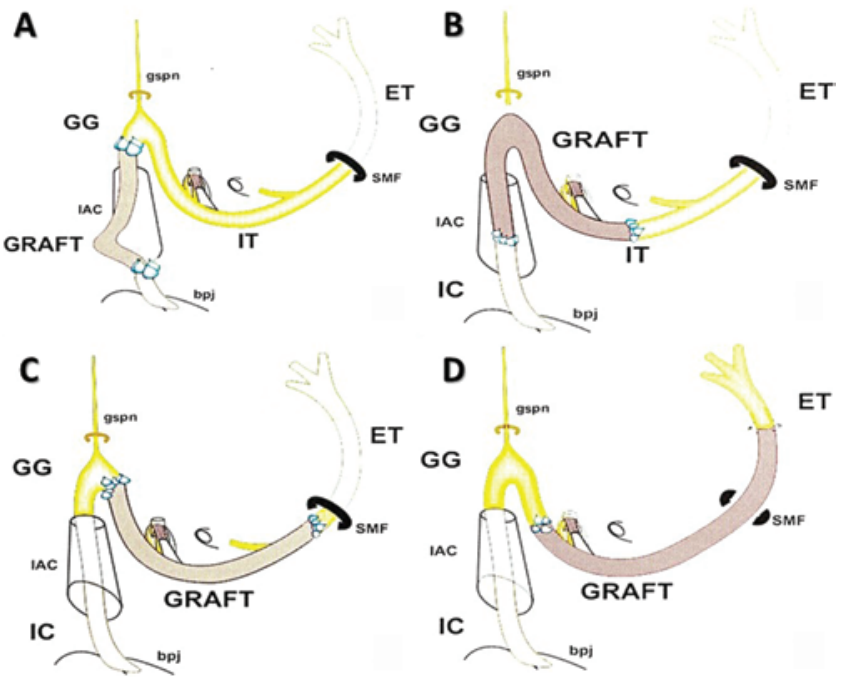

FIG. 5. A: Intradural coaptation. B: Transdural coaptation. C and D: Extradural coaptation. bpj = brainstem-pontine junction; $E T=$ extratemporal part of the facial nerve; $G G=$ geniculate ganglion; gspn = greater superficial petrosal nerve; $I \mathrm{C}=$ intracranial part of the facial nerve; IT = intratemporal part of the facial nerve; SMF = stylomastoid foramen. Figure is available in color online only. 


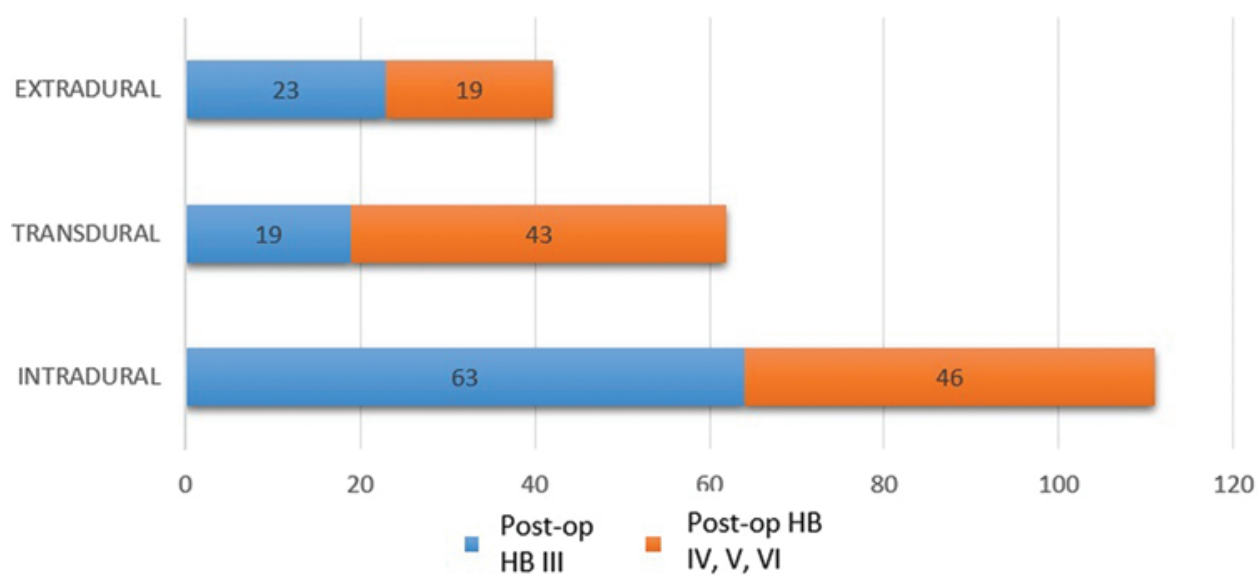

FIG. 6. Postoperative results in the 3 categories based on the site of coaptation. Figure is available in color online only.

In 1885, Albert Einige described the first 2 cases of SN reconstruction for a $3-\mathrm{cm}$ median and a $10-\mathrm{cm}$ ulnar nerve defect. ${ }^{10}$ Seventy years later, in 1955, John Conley performed the first case of greater auricular nerve interposition of the FN following total parotidectomy. ${ }^{9}$ Recent studies have shown that cable nerve graft interpositioning provides as good a result as a primary end-to-end coaptation. $2,17,47,50$ However, the best possible postoperative outcome is HB Grade III, regardless of the graft material used or the technique employed, because the frontal muscle function rarely recovers and a certain degree of synkinesis is unavoidable after grafting., ${ }^{2,30,39}$

The factors that could influence the results of FN reconstruction are discussed below.

\section{Pathophysiology}

Nerve regeneration after grafting does not involve mitosis and multiplication of nerve cells. Instead, the cell body restores nerve continuity by growing a new axon. The cable nerve graft acts as a nerve conduit with empty endoneurial tubes, a reserve of viable Schwann cells, and nerve growth factors through which the regenerating axons can be directed. The use of stem cells and nerve conduits to substitute for the nerve grafts has been tried with promising results. However, a sensory nerve graft is still considered a better alternative as it is an excellent biocompatible, resorbable nerve conduit with a basal lamina, preformed guidance channels, a reserve of viable Schwann cells, and nerve growth factors. ${ }^{47}$

\section{Demographic Factors}

It has been reported that after a neural injury, women tend to maintain the viability of the facial musculature longer than men; hence, the results of grafting could be better in women. ${ }^{19}$ This finding was supported by our study, wherein more females $(60 \%)$ than males $(46 \%)$ had a significantly better outcome in recovering to HB Grade III $(\mathrm{p}=0.04)$. Kimata et al. ${ }^{27}$ reported that outcomes of FN grafting were better in younger patients. In our series, postoperative HB Grade III function was more frequent in the group with an age $\leq 40$ years $(60 \%)$ than in the group with an age $>40$ years $(45 \%)$, but the difference was not statistically significant.

\section{Duration of Paralysis}

One of the most important factors that determines the ultimate success of any reinnervation procedure is the duration of facial paralysis. An interrupted FN should be promptly surgically repaired either with a direct endto-end coaptation when feasible or with an interposition graft. Facial muscles completely denervated for less than a year respond to nerve grafting. The response to reinnervation after a year of paralysis diminishes significantly and becomes unpredictable. In cases of incomplete denervation, the facial muscles can remain viable for longer and may respond to reinnervation techniques. ${ }^{6}$ We perform cable graft interpositioning of the FN only in cases of paralysis lasting 1 year or less. In all cases with paralysis lasting longer than 1 year, the patients are managed with a hypoglossal or masseteric nerve coaptation with the FN.

\section{Tumor Factors}

The FN, as most motor nerves, is quite resistant to infiltration by pathologies. Axon and Ramsden ${ }^{4}$ stated that HB Grade I FN function could be maintained until the motor neuron reserve is $\geq 10 \%$. Neuronal degeneration and axonal demyelination is counterbalanced with the collateral sprouting and hypertrophy of the innervated muscle fibers. Furthermore, the absence of epineurium around the CPA and IAC segments of the FN allows effacement of the nerve fibers and spreading of the nerve over large tumors. Facial nerve function was preserved until more than $50 \%$ of the motor neurons had been degenerated. ${ }^{4,26}$ In slowgrowing pathologies such as VS and meningioma, the FN fibers are stretched slowly over many months, eventually leading to kinking. This may lead to a disruption in axoplasmic flow, which is a Type 1 reversible nerve injury. When such a nerve is interrupted and grafted, a satisfactory outcome is achievable since all the fibers are still viable and available for regrowth. However, other variable factors, such as the loss of blood supply to the nerve, tumor infiltration, or the inflammatory insult, are likely to influence the results of grafting. In our study, we observed that slow-growing tumors such as TJPs, VSs, and meningiomas had favorable outcomes (HB Grade III in 57.1\%, $56.6 \%$, and $80 \%$, respectively). Data analysis revealed that the rate of recovery to HB Grade III FN function is better 
when the preoperative nerve function is HB Grade I, and this finding was statistically significant ( $p=0.02$; Fig. 3 ). This finding has been validated in other series as well..$^{2,31}$ Hence, preoperative FN function is a very important factor in determining the outcome of FN grafting. Statistically, the size of the tumor, excluding PBCs and temporal bone malignancies, did not significantly influence the outcome of grafting $(\mathrm{p}=0.81)$.

The inflammatory insult to the FN caused by a cholesteatoma is very high, leading to interruption of the nerve by scarring. ${ }^{1}$ In our series of PBCs, only $38 \%$ of the nerves grafted were associated with a postoperative HB Grade III. The results were even worse in temporal bone malignancies, as none of the grafted cases recovered to Grade III postoperatively. This result could be attributed to the fact that apart from the infiltrative nature of the disease, the grafted nerves were subjected to further insult from the postoperative radiation, although none of the patients have developed a recurrence so far.

\section{Characteristics of the Donor Nerve Graft}

The SN has emerged as an ideal graft material because of its ease of access, abundant length, sufficient thickness, branching (which can be used to reconstruct the peripheral branches of the FN), and its ability to be harvested outside of the primary operating field and thus reduce surgical time. However, the greater auricular nerve remains a preferred choice if the primary surgical incision extends into the lateral neck. The fascicular arrangement of the FN becomes prominent after the geniculate ganglion wherein the nerve also acquires a perineurium. Microscopically, the fascicle count of the $\mathrm{FN}$ in the mastoid segment is between 4 and $16 .{ }^{8}$ Likewise, the SN consists of 6-12 fascicles ${ }^{30,51}$ and hence can be considered to be a compatible graft. Remember, however, that while small-diameter grafts spontaneously revascularize, large-diameter grafts (for example, the SN or greater auricular nerves) do so incompletely due to central necrosis with subsequent endoneurial fibrosis, and this could be a reason for suboptimal results. ${ }^{5}$

\section{Site of Reconstruction}

Studies have suggested that the more proximal the site of nerve transection is to the cell body, the more intense the damage to the cell body located within the central nervous system and hence the lower the chance of nerve survival. ${ }^{15,35,47}$ In our study, however, the intradural group, comprising mostly slow-growing tumors, had significantly better outcomes than the transdural group, which comprised mostly inflammatory pathologies. This finding could be attributed to the fact that most of the intradural tumors had preoperative HB Grade I FN function, whereas the other groups had worse preoperative grades. On subgroup analysis, $80 \%$ of the intradural coaptations had preoperative HB Grade I nerve function. In comparison, only $35 \%$ of the transdural and $3.22 \%$ of the extradural group had preoperative HB Grade I.

\section{Technique of Reconstruction}

Delicate maneuvers of nerve approximation like peri- neurial, group funicular, and epineurial suturing are very difficult to perform in the depths of a pulsating CPA and even more so by a tired surgeon subsequent to a long and frequently laborious procedure. ${ }^{50}$ Furthermore, the FN lacks a true fascicular organization until the geniculate ganglion, ${ }^{2,8,9,29}$ and this makes it practically impossible to perform any kind of epi- or perineurial suturing until the geniculate ganglion. Hence, we prefer to use stitch-less fibrin glue for coaptation in the intradural and transdural anastomoses. ${ }^{43}$ The success of this technique has been researched and replicated by other authors..$^{3,739,49}$ Suturing is reserved only for extradural coaptation.

\section{Length of Nerve Graft}

An HB Grade III outcome was best achieved with nerve grafts of a shorter length $(\leq 4 \mathrm{~cm})$. The reason could be multifactorial. First, a majority of these grafts were from the intradural group, which had a higher incidence of preoperative HB Grade I. Second, in intradural coaptation, alignment of the graft is almost always in a linear or curvilinear orientation, whereas in transdural and extradural coaptation, the nerve graft takes a tortuous course. This tortuosity could lead to kinking of newly growing nerve fibers. Third, the shorter the nerve graft, the less effort required at the neoformation of fibers. In the extradural group, as compared with the intradural and transdural groups, the lower incidence of success could be attributable to the fact that diseases in the temporal bone, such as PBCs, are proven to have an unfavorable prognosis after grafting.

\section{Other Influencing Factors}

Suboptimal results could be due to possible scarring at the site of coaptation and/or the unavailability of adequate nerve fibers for regeneration. ${ }^{36,50}$ Another important factor is the exclusive use of sensory nerves as donors to repair motor nerves. Recent investigations have demonstrated that Schwann cells derived from sensory nerves, as compared with those derived from motor neurons, have different expression patterns for growth factors. ${ }^{18}$ This means that the regenerating motor neurites get very little support from the Schwann cells of the donor. They must grow without support from the graft pathway until they can be rescued by contact with the native nerve tissue distal to the graft. ${ }^{34}$ Tissue engineering techniques using nerve generation conduits made of biodegradable materials with motor neuron-specific growth factor could prove to be a solution to this in the future. ${ }^{24,37,38}$

\section{Review of Literature}

We performed a review of the literature on all studies reporting on the results of FN grafting from 1990 to the present date. A PubMed search was done using relevant keywords and yielded 18 relevant articles. In cases of overlapping data in multiple articles, we selected the data from the latest article. Thirteen important articles were reviewed, and the results were compared with those in our study (Table 2). With 213 patients, ours was the largest series. Given the paucity of cases, most authors preferred to report FN grafting for all pathologies of the skull base 
TABLE 2. Comparison of outcomes in the literature on FN reconstruction by cable nerve graft interpositioning

\begin{tabular}{lccccccc}
\hline & No. of & & \% Preop Facial & \multicolumn{4}{c}{ Postop FN function (\%) } \\
\cline { 5 - 8 } Authors \& Year & Cases & Pathology & Palsy Cases & HB III & HB IV & HB V & HB VI \\
\hline Stephanian et al., 1992 & 24 & Multiple & 63 & 46 & 36 & 18 & - \\
\hline Arriaga et al., 1992 & 8 & Multiple & 75 & 13 & 37 & 25 & 25 \\
\hline King et al., 1993 & 12 & Multiple & NS & 41 & 17 & 25 & 17 \\
\hline Janecka et al., 1993 & 14 & Multiple & 78 & 36 & 43 & 7 & 14 \\
\hline Saeed \& Ramsden, 1996 & 12 & NS & NS & 83 & 0 & 1 & 1 \\
\hline Samii \& Matthies, 1997 & 42 & VS & 21 & 73 & 21 & 6 & - \\
\hline Magliulo et al., 1998 & 6 & PBC & 100 & 67 & - & 33 & - \\
\hline Gidley et al., 1999 & 25 & Multiple & 48 & 68 & 16 & 4 & 8 \\
\hline Malik et al., 2005 & 25 & Multiple & 100 & 56 & 54 & - & - \\
\hline Kimata et al., 2005 & 6 & Multiple & 1 & 83 & 17 & - & - \\
\hline Bozorg Grayeli et al., 2005 & 25 & Multiple & 77 & 5 & 75 & 10 & 10 \\
\hline Günther et al., 2010 & 21 & FN & 71 & 86 & 9 & 5 & - \\
\hline Wang et al., 2013 & 13 & VS & 0 & 77 & 23 & - & - \\
\hline Present study & 213 & Multiple & 50.7 & 51 & 22 & 9 & 18 \\
\hline NS = not specified. & & & & & &
\end{tabular}

combined. The rate of HB Grade III function ranges from $5 \%$ to $86 \%$. The results of the present study were consistent with those in the literature, with $51 \%$ of patients achieving HB Grade III. Postoperatively, most authors managed to achieve HB Grade III in at least $50 \%$ of their patients.

\section{Conclusions}

Cable graft interpositioning is a convenient and wellaccepted procedure for immediate restoration of the FN. Our results, over a large number of patients, show that the stitch-less fibrin glue-aided coaptation technique yields good results. The best possible postoperative result achieved in our series was an HB Grade III. The chances of a good postoperative result increase when FN function is normal preoperatively. Slow-growing tumors of the CPA had a favorable outcome after grafting.

\section{References}

1. Amar MS, Wishahi HF, Zakhary MM: Clinical and biochemical studies of bone destruction in cholesteatoma. $\mathbf{J}$ Laryngol Otol 110:534-539, 1996

2. Arriaga MA, Brackmann DE: Facial nerve repair techniques in cerebellopontine angle tumor surgery. Am J Otol 13:356359, 1992

3. Attar BM, Zalzali H, Razavi M, Ghoreishian M, Rezaei M: Effectiveness of fibrin adhesive in facial nerve anastomosis in dogs compared with standard microsuturing technique. J Oral Maxillofac Surg 70:2427-2432, 2012

4. Axon PR, Ramsden RT: Facial nerve injury caused by vestibular Schwannoma compression: severity and adaptation to maintain normal clinical facial function. Am J Otol 20:763769, 1999

5. Best TJ, Mackinnon SE, Evans PJ, Hunter D, Midha R: Peripheral nerve revascularization: histomorphometric study of small- and large-caliber grafts. J Reconstr Microsurg 15:183-190, 1999

6. Boahene K: Reanimating the paralyzed face. F1000Prime Rep 5:49, 2013

7. Bozorg Grayeli A, Mosnier I, Julien N, El Garem H, Bouc- cara D, Sterkers O: Long-term functional outcome in facial nerve graft by fibrin glue in the temporal bone and cerebellopontine angle. Eur Arch Otorhinolaryngol 262:404-407, 2005

8. Captier G, Canovas F, Bonnel F, Seignarbieux F: Organization and microscopic anatomy of the adult human facial nerve: anatomical and histological basis for surgery. Plast Reconstr Surg 115:1457-1465, 2005

9. Conley JJ: Facial nerve grafting in treatment of parotid gland tumors; new technique. AMA Arch Surg 70:359-366, 1955

10. Einige AE: Operationen an Nerven. Wied Med Presse 26:1285-1288, 1885

11. Fisch U: Infratemporal fossa approach to tumours of the temporal bone and base of the skull. J Laryngol Otol 92:949967, 1978

12. Fisch U, Fagan P, Valavanis A: The infratemporal fossa approach for the lateral skull base. Otolaryngol Clin North Am 17:513-552, 1984

13. Fisch U, Pillsbury HC: Infratemporal fossa approach to lesions in the temporal bone and base of the skull. Arch Otolaryngol 105:99-107, 1979

14. Gidley PW, Gantz BJ, Rubinstein JT: Facial nerve grafts: from cerebellopontine angle and beyond. Am J Otol 20:781788, 1999

15. Goldberg JL, Barres BA: The relationship between neuronal survival and regeneration. Annu Rev Neurosci 23:579-612, 2000

16. Günther M, Danckwardt-Lillieström N, Gudjonsson O, Nyberg G, Kinnefors A, Rask-Andersen H, et al: Surgical treatment of patients with facial neuromas-a report of 26 consecutive operations. Otol Neurotol 31:1493-1497, 2010

17. Hohman MH, Kleiss IJ, Knox CJ, Weinberg JS, Heaton JT, Hadlock TA: Functional recovery after facial nerve cable grafting in a rodent model. JAMA Facial Plast Surg 16:2024,2014

18. Höke A, Redett R, Hameed H, Jari R, Zhou C, Li ZB, et al: Schwann cells express motor and sensory phenotypes that regulate axon regeneration. J Neurosci 26:9646-9655, 2006

19. Hontanilla B, Marre D: Retrospective study of the functional recovery of men compared with that of women with longterm facial paralysis. Br J Oral Maxillofac Surg 51:684688, 2013 
20. House JW, Brackmann DE: Facial nerve grading system. Otolaryngol Head Neck Surg 93:146-147, 1985

21. House WF: Transcochlear approach to the petrous apex and clivus. Trans Sect Otolaryngol Am Acad Ophthalmol Otolaryngol 84:ORL927-ORL931, 1977

22. House WF, De la Cruz A, Hitselberger WE: Surgery of the skull base: transcochlear approach to the petrous apex and clivus. Otolaryngology 86:ORL-770-ORL-779, 1978

23. House WF, Hitselberger WE: The transcochlear approach to the skull base. Arch Otolaryngol 102:334-342, 1976

24. Inada Y, Hosoi H, Yamashita A, Tatsumi H, Notazawa S, Kanemaru S, et al: Regeneration of peripheral motor nerve gaps with a polyglycolic acid-collagen tube: technical case report. Neurosurg 61:E1105-E1107, 2007

25. Janecka IP, Sekhar LN, Sen CN: Facial nerve management in cranial base surgery. Laryngoscope 103:291-298, 1993

26. Kartush JM, Lundy LB: Facial nerve outcome in acoustic neuroma surgery. Otolaryngol Clin North Am 25:623-647, 1992

27. Kimata Y, Sakuraba M, Hishinuma S, Ebihara S, Hayashi R, Asakage T: Free vascularized nerve grafting for immediate facial nerve reconstruction. Laryngoscope 115:331-336, 2005

28. King TT, Sparrow OC, Arias JM, O’Connor AF: Repair of facial nerve after removal of cerebellopontine angle tumors: a comparative study. J Neurosurg 78:720-725, 1993

29. Lacombe H: [Functional anatomy of the facial nerve.] Neurochirurgie 55:113-119, $2009(\mathrm{Fr})$

30. Lee MC, Kim DH, Jeon YR, Rah DK, Lew DH, Choi EC, et al: Functional outcomes of multiple sural nerve grafts for facial nerve defects after tumor-ablative surgery. Arch Plast Surg 42:461-468, 2015

31. Leonetti JP, Anderson DE, Marzo SJ, Origitano TC, Petruzzelli GJ: Intratemporal grafting of the facial nerve following lateral skull base tumor resection. Skull Base 17:181-186, 2007

32. Magliulo G, Terranova G, Sepe C, Cordeschi S, Cristofar P: Petrous bone cholesteatoma and facial paralysis. Clin Otolaryngol Allied Sci 23:253-258, 1998

33. Malik TH, Kelly G, Ahmed A, Saeed SR, Ramsden RT: A comparison of surgical techniques used in dynamic reanimation of the paralyzed face. Otol Neurotol 26:284-291, 2005

34. Martini R, Schachner M, Brushart TM: The L2/HNK-1 carbohydrate is preferentially expressed by previously motor axon-associated Schwann cells in reinnervated peripheral nerves. J Neurosci 14:7180-7191, 1994

35. Novikova L, Novikov L, Kellerth JO: Effects of neurotransplants and BDNF on the survival and regeneration of injured adult spinal motoneurons. Eur J Neurosci 9:2774-2777, 1997

36. Ozmen OA, Falcioni M, Lauda L, Sanna M: Outcomes of facial nerve grafting in 155 cases: predictive value of history and preoperative function. Otol Neurotol 32:1341-1346, 2011

37. Patel M, Mao L, Wu B, VandeVord P: GDNF blended chitosan nerve guides: an in vivo study. J Biomed Mater Res A 90:154-165, 2009

38. Pfister LA, Papaloïzos M, Merkle HP, Gander B: Nerve conduits and growth factor delivery in peripheral nerve repair. $\mathbf{J}$ Peripher Nerv Syst 12:65-82, 2007

39. Ramos DS, Bonnard D, Franco-Vidal V, Liguoro D, Darrouzet V: Stitchless fibrin glue-aided facial nerve grafting after cerebellopontine angle schwannoma removal: technique and results in 15 cases. Otol Neurotol 36:498-502, 2015

40. Saeed SR, Ramsden RT: Rehabilitation of the paralysed face: results of facial nerve surgery. J Laryngol Otol 110:922925, 1996

41. Samii M, Matthies C: Management of 1000 vestibular schwannomas (acoustic neuromas): the facial nerve-preservation and restitution of function. Neurosurgery 40:684695, 1997

42. Sanna M, Essam S, Khrais T, Mancini F, Piazza P, Russo A, et al (eds): Atlas of Microsurgery of the Lateral Skull Base. Stuttgart: Thieme, 2007

43. Sanna M, Jain Y, Falcioni M, Mancini F, Romano G: Facial nerve grafting in the cerebellopontine angle. Laryngoscope 114:782-785, 2004

44. Sanna M, Khrais T, Mancini F, Russo A, Taibah A: Facial nerve management in middle ear and external auditory canal carcinoma, in Sanna M, Khrais T, Mancini F, et al (eds): The Facial Nerve in the Temporal Bone and Lateral Skull Base Microsurgery. Stuttgart: Thieme, 2006, pp 259-277

45. Sanna M, Mazzoni A, Saleh E, Taibah A, Mancini F: The system of the modified transcochlear approach: a lateral avenue to the central skull base. Am J Otol 19:88-98, 1998

46. Sanna M, Shin SH, Piazza P, Pasanisi E, Vitullo F, Di Lella F, et al: Infratemporal fossa approach type a with transcondylar-transtubercular extension for Fisch type C2 to C4 tympanojugular paragangliomas. Head Neck 36:1581-1588, 2014

47. Slutsky DJ: A practical approach to nerve grafting in the upper extremity. Atlas Hand Clin 10:73-92, 2005

48. Stephanian E, Sekhar LN, Janecka IP, Hirsch B: Facial nerve repair by interposition nerve graft: results in 22 patients. Neurosurgery 31:73-77, 1992

49. Wang Q, Hua Q, Wang S: [Application of fibrin glue in facial nerve repair.] Sheng Wu Yi Xue Gong Cheng Xue Za Zhi 24:612-614, 2007 (Chinese)

50. Wang Z, Zhang Z, Huang Q, Yang J, Wu H: Long-term facial nerve function following facial reanimation after translabyrinthine vestibular schwannoma surgery: A comparison between sural grafting and VII-XII anastomosis. Exp Ther Med 6:101-104, 2013

51. Wolford LM, Stevao EL: Considerations in nerve repair. Proc Bayl Univ Med Cent 16:152-156, 2003

\section{Disclosures}

The authors report no conflict of interest concerning the materials or methods used in this study or the findings specified in this paper.

\section{Author Contributions}

Conception and design: He, Balasubramanian, Sanna. Acquisition of data: He, Prasad, Balasubramanian, Piccirillo, Taibah, Russo. Analysis and interpretation of data: He, Prasad, Balasubramanian, Taibah, Sanna. Drafting the article: Prasad, Balasubramanian. Critically revising the article: He, Prasad, Taibah, Russo. Reviewed submitted version of manuscript: He, Prasad, Piccirillo, Russo, Sanna. Approved the final version of the manuscript on behalf of all authors: He. Statistical analysis: He, Prasad, Balasubramanian. Administrative/technical/material support: Piccirillo, Russo, Sanna. Study supervision: He, Sanna.

\section{Correspondence}

Jingchun He, Department of Otorhinolaryngology, Shanghai First People's Hospital, Shanghai Jiao Tong University, 100 Haining Rd., Shanghai 200080, China. email: entdoctorhe@163.com. 